\title{
Assessing the role of electricity networks in bushfire ignitions: estimation of current and prospective performance
}

\author{
Carolyn Huston $^{\mathrm{a}}$, Simon Dunstall ${ }^{\mathrm{a}}$, Gary Towns ${ }^{\mathrm{b}}$, Alec Stephenson ${ }^{\mathrm{a}}$, Stuart Woodman ${ }^{\mathrm{a}}$ and \\ Ashley Hunt ${ }^{\mathrm{c}}$ \\ ${ }^{\mathrm{a}}$ CSIRO, Clayton, Victoria, 3169 \\ ${ }^{\mathrm{b}}$ Facio Pty. Ltd., Mentone, Victoria, 3194 \\ ${ }^{\mathrm{c}}$ Powerline Bushfire Safety Commission, Melbourne, Victoria, 3000 \\ Email: carolyn.huston@csiro.au
}

\begin{abstract}
Subsequent to the Black Saturday fires in 2009, the Victorian government created the Powerline Bushfire Safety Program (PBSP), which, among other things, is focused on the identification and prevention of faults and ignitions caused by electricity distribution networks as a way to reduce bushfire risk on high fire days. Successfully achieving this goal first involves obtaining or creating a dataset capable of evaluating the current fault and ignition situation in Victorian power networks. Subsequently, this information on power network fault/ignition performance provides a basis for predicting future fault/ignition performance on the network. Over time new network assets are created; are moved; or are modified to apply new fire preventative measures as required by new regulatory requirements. A positive side-effect of the development of this network performance data and predicted performance capability is the ability to attribute changes in bushfire events to policy and equipment changes on the distribution network.

The data needed to assess current (and historic) performance of electricity distribution systems includes information on pole locations; line locations; technology status; electric fault location and time data; conversion from fault to ignition under different meteorologic conditions; meteorological conditions at the time and location of recorded faults; and so on. Collection of this data had to be coordinated between multiple agencies including electrical distribution companies, and state and federal government agencies. Such data was then processed to allow an estimation of fault/ignition rates for different equipment under different meteorologic conditions so that the expected role of the electrical network in bushfires losses is estimable. Due to stratification along meteorologic variables when considering network performance, we can predict how network changes will interact with climate change in terms of expected bushfire rates caused by electricity. Our calculations and modelling form an important part of the work discussed. Additionally, we also consider lessons learned about compiling data from different sources entities. We believe there is a fundamental need to develop relationships and synergies with multiple organizations if we are to attribute changes in natural hazards to various causes.
\end{abstract}

Keywords: Bushfires, electricity systems, quantitative risk modelling 


\section{INTRODUCTION}

Bushfires caused by electricity infrastructure have been involved in a disproportionate number of bushfire related fatalities in Victoria, Australia. Well-known fatality causing bushfires that involved electrical infrastructure ignitions include Ash Wednesday in 1983, and Black Saturday in 2009. Due to the association between fatalities and electrically ignited bushfires in Victoria, we have been investigating how to assess bushfire risk ignition across Victorian electricity networks, and to investigate the effectiveness of mitigation strategies. In conjuction with the Victorian government's PBSP, this collection of data and mathematical approaches has been termed the Risk Reduction Model (RRM). Scientifically, a number of beneficial side-effects are occurring as a result of this RRM investigation.

\subsection{Data collection}

One such side-effect is in the construction of a relevant, comprehensive, and interdependent databases containing observational data that we have collected, cleaned and organized from multiple contributing sources and organizations. These data facilitate our understanding of the relationships between electrical distribution assets and bushfire faults and ignitions. Constructing the databases involved coordinating data collection, cleaning, and organization from multiple agencies. Integrating this data posed many challenges due to differences in notation and variables included; completeness of records; organizational approaches; overall quality; ease of access and us for outside organizations and purposes; difficulty in matching records; etc.

\subsection{Attribute change in electrical ignitions}

The data sources described above are historic, and provide information about past performance of electricity distribution assets and related variables. A key goal is also to predict future performance of existing electrical assets and new electrical assets under future asset configurations, operational strategies, and weather conditions. The component of RRM that deals with operation of future potential asset configurations has been defined as the Future Assets Model (FAM). This model is constructed based on observational data regarding the performance of current electrical asset configurations; experimental information about the performance of technologies that could be deployed on electrical networks; and expert judgement and calculations that allow us to extend the scope of experimental results based on our best understanding of factors contributing to fires such as energy discharges, fault configurations, interactions with weather, and so on.

The FAM allows us to investigate the performance of the network under a variety of potential network configurations that could be operated in future. Generally, the asset replacements under consideration reduce the risk of faults and subsequently ignitions that could lead to bushfires. This allows us to attribute/detect change in bushfire rates based on distribution network changes. The RRM can also provide a basis for evaluating and improving current network performance estimates of current FAM predictions. Such evaluation assumes that replacements are made in a known time frame and future data collection and report availability is consistent with what we currently use.

\subsection{Literature review}

Typically, studies considering bushfire incidence and detecting and understanding bushfire hazards focus on lightning and anthropogenic causes. For example, several studies look at environmental factors that contribute to varying rates of human-caused versus lightning caused fires (Magnussen and Taylor, 2012; Padilla and VegaGarcia, 2011; Penman et al., 2013; Plucinski et al., 2013; Reineking et al., 2010; Wang and Anderson, 2010). Most studies are also generated in regions outside of Australia (Magnussen and Taylor, 2012; Padilla and Vega-Garcia, 2011; Reineking et al., 2010; Wang and Anderson, 2010), although there are a few references that focus on lightning initiated ignitions in Victoria (Dowdy and Mills, 2012a,b). Contrary to these other studies, the Victorian government's RRM approach exclusively considers electrically caused bushfires. This focus on the electrical system is due to a goal of better understanding bushfires that cause the highest number of fatalities rather than the highest number of fire starts. To the best of our knowledge, this PBSP commissioned study is therefore one of a few that focuses on exploring bushfire causes in Australia. It is also one of the first internationally that is specifically considering fires caused by electrical infrastructure as opposed to the more common lightning and human caused fire starts. 


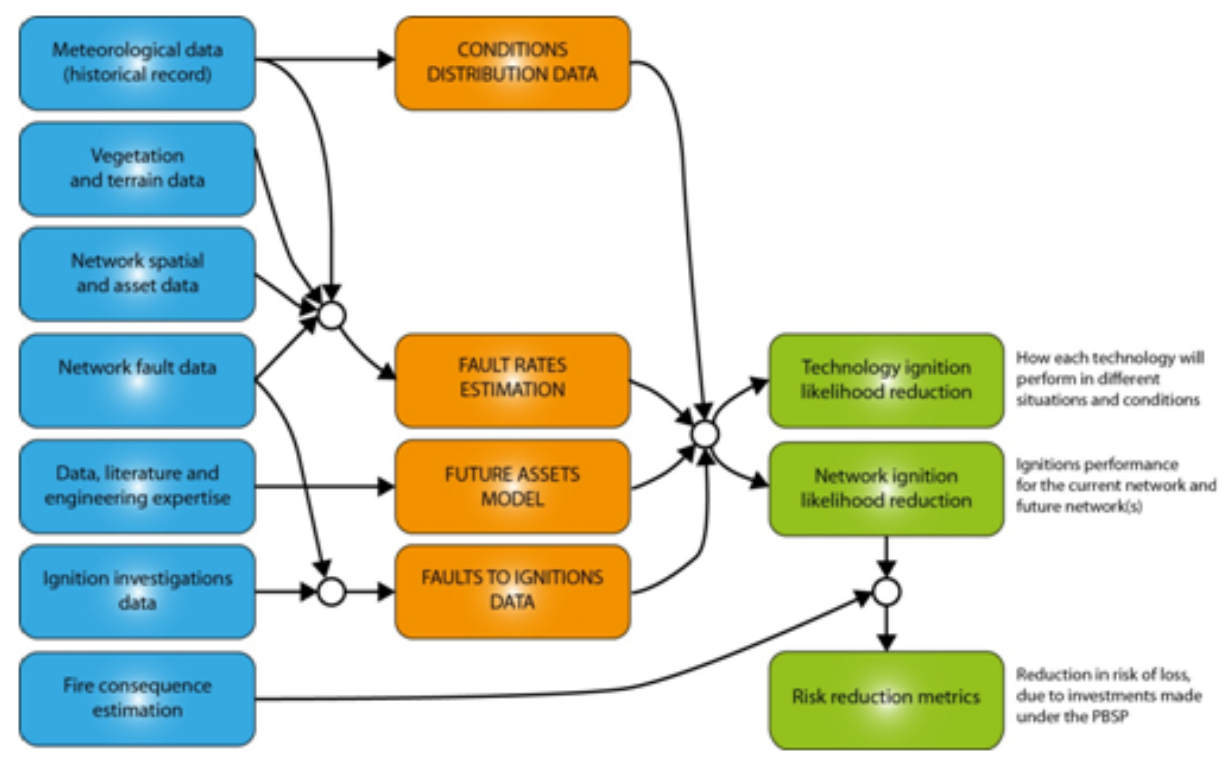

Figure 1. Data, models and outputs relevant to the likelihood and risk modelling approach

\subsection{Motivating example}

This work was motivated by the desire of the Victorian governments Powerline Bushfire Safety Program (PBSP) to develop a systematic approach to quantify the likelihood (rates) of faults and fire ignitions on the Victorian electricity distribution system. The goal is to use the information to target activities of the Victorian Powerline Replacement Fund (PRF) and to calculate the impact of a range of PBSP programs in reducing powerline related bushfire risk.

\section{METhods AND DATA}

Below we discuss some of the key data and processes/methods that are used to calculate the desired risk reduction and risk assessment metrics (here risk is defined as the expected ignition rate multiplied by the potential fire loss consequence). The general flow of data to information is illustrated in Figure 1.

For basic fault rate estimation, the different data sources can be generally divided into meteorological/condition data; situational data; and network related data. Many of the future technologies that will be deployed based on new regulations are not yet associated with any performance data in Victorian field conditions. Instead, these are estimated based on existing literature and data; engineering expertise; and some privately commissioned experimental data regarding ignitions on key new technologies. The final data component is obtained from bushfire spread simulations, and is the estimated consequence (in terms of the number of structures affected by fire) of a bushfire ignited at each cell of a grid spanning the state under Ash Wednesday weather conditions.

\subsection{Condition}

Condition data references environmental data pertinent to the model that can change on a daily basis and often within a fire season. So-called condition variables are based on meteorological conditions: wind speed, temperature, environmental dryness (KBDI), and relative humidity. These conditions are then inputs to calculating Fire Danger Index values as needed. Moisture case is a separately considered aspect of condition that is a specific input to the FAM. It is intended to represent the degree to which moisture might be present along a conduction path for electricity between electrical system assets and vegetation. For example, dry conditions result in higher electrical impedance. We consider normal, dry, and very dry cases in the model.

Weather data is binned into discrete categories for all of the variables above, giving a discrete set of potential weather inputs at each location of interest. Knowing these condition categories, we can then estimate the length of time a given location spends in each set of weather conditions. In warmer summers, more time will be spent in bins representing warmer dryer weather. In this way the model is able to normalize fault rates across different weather conditions. 
Currently, we are using weather data provided by the Bureau of Meteorology about data collected at operating weather stations across the state of Victoria. We have all historic weather data up until 2014. Although weather stations sometimes report and collect data as often as every half-hour, we bin data on a daily basis. To create an empirical distribution of weather conditions for network asset locations, we locate network assets to their nearest weather station.

\subsection{Situation}

Situation data is environmental data that changes slowly, or does not change at all and can be considered constant within a fire season. Most pertinent among these are the terrain and type(s) of vegetation that are located near electrical asset locations. Specifically, four vegetation types ("forest", "grassland", "mixed vegetation", and "unburnable") and a measure of terrain based on slope ("flat" or "undulating") are used. As with condition data, this gives a finite set of bins. The number of poles (or length of line) associated with each type of situation information can therefore be collated across the electrical network.

The situation data we are using represents 4 different vegetation types. Slope was calculated based on topographic information. Note that urban areas are not generally considered in the RRM modelling as these are considered relatively "unburnable", so while electrical assets might still cause fires it is highly unlikely that they would evolve into bushfires.

\subsection{Electrical assets}

Electrical asset information has been provided by relevant Victorian electricity businesses. Electrical asset information includes both asset state and spatial components. Any given asset is made up of certain characteristics that collectively define its state. Such assets also have a known location in space and a network location relative to other assets. The electricity-distribution powerlines of interest are single-phase $12.7 \mathrm{kV}$ AC Single Wire Earth Return (SWER) powerlines, and two or three phase 22kV AC multi-phase powerlines. Multi-phase lines are made up of two or three bare-wire (i.e., uninsulated) conductors each carrying electrical current. SWER lines consist of one bare-wire current-carrying conductor.

Electrical assets are formed into a hierarchical network. At the root of the hierarchy considered in our model are zone substations (synonymously, zonesubs), where the higher-voltage (e.g., 500kV) electricity transmission system meets the lower-voltage (e.g., $22 \mathrm{kV}$ ) electricity distribution system. Our interest is exclusively on the distribution side. One or more feeders eminate from zone substations on the distribution-side: typically there might be four to eight feeders per zone substation. In turn, feeders decompose into sections of the electrical network. Sections of an electrical network are made up of individual poles and spans of conductor (line): typically a section covers 20 to 200 poles of contiguous powerline.

Technology treatments with the capacity to reduce fire ignition likelihood which are applied at the zone substation level will affect one or more of the feeders, and tend to decrease the fire-related risk of all sections of each such feeder. Treatments at the section level will affect the associated poles and lines. Treatments applied to specific poles and lines will protect only these poles and lines.

\subsection{Network fault rates/incidents}

Faults are unplanned and unfavourable events on the electricity network — such as breakage or impact damage to conductors or pole-mounted equipment, pole-top fires, or activation of electrical protection equipment which often lead to unsafe conditions and/or an interruption of electricity supply to customers. Records of past electrical faults on the network have been provided by relevant businesses. Based on available data, some faults can be mapped to a particular pole or section of line, while others can only be associated with a feeder or zone substation. For data analysis purposes, individual faults are therefore sometimes "distributed" across many individual network assets. The rate of faults are therefore often calculated based on such distributed faults, where the fault is distributed across a range of situation and sometimes condition combinations.

In addition to being associated with condition and situation variables, faults are classified according to eight cause-categories (for example, animal caused, vegetation caused, etc.), up to around a dozen sub-cause categories (e.g., animal on asset structure), and a similar number of asset-impact categories (e.g., broken conductor). Faults, considered by cause and sub-cause and/or asset-impact, tend to be specific to either lines or poles. Consequently, fault rates are estimated in terms of either a pole rate or line rate for a given cause, sub-cause and impact, and for each combination of situations and conditions. These rates can then be combined to give the estimated fault rate for a given length of line with known asset type(s) in a specified vegetation class and 
C. Huston et al., Assessing electricity network roles in bushfire ignition

terrain class, and under specified environmental conditions.

Table 1. Electrical asset types and configurations considered when assessing bushfire risk

\begin{tabular}{|c|c|}
\hline Asset Type & Notes \\
\hline Bare Wire & $\begin{array}{l}\text { This is the status quo, assuming bare-wire conductors spanning wooden poles } \\
\text { fitted with steel crossarms. Fuse or Automatic Circuit Reclosers (ACR) with } \\
\text { "slow acting" settings as electrical (safety) protection. }\end{array}$ \\
\hline Bare \& ACR Op change & $\begin{array}{l}\text { ACRs have operational settings adjusted on high fire days to minimize ignition } \\
\text { likelihood (at the expense of supply reliability). }\end{array}$ \\
\hline Bare \& HiZ & $\begin{array}{l}\text { Status quo, but with the addition (at a feeder or section level) of detection tech- } \\
\text { nology for high-impedence ("HiZ") vegetation-related faults. Such technology } \\
\text { is proposed but not yet existing. }\end{array}$ \\
\hline Bare ACR Op \& HiZ & $\begin{array}{l}\text { Bare wire conductors with ACR operational changes and "HiZ" protection at } \\
\text { the section level. }\end{array}$ \\
\hline Bare \& REFCL & $\begin{array}{l}\text { Bare wire conductors, with new Rapid Earth Fault Current Limiter (REFCL) } \\
\text { electrical protection technology installed at the zonesub/feeder level. }\end{array}$ \\
\hline Bare, REFCL \& ACR & $\begin{array}{l}\text { Bare wire conductors with ACR (op change) protection on a section and RE- } \\
\text { FCL protection at the zonesub/feeder level. }\end{array}$ \\
\hline Bare REFCL, ACR \& HiZ & $\begin{array}{l}\text { Bare wire conductors with ACR (op change), high impedence fault detection } \\
\text { and REFCL. }\end{array}$ \\
\hline $\begin{array}{l}\text { Insulated OH Bare Eqpt w } \\
\text { ACR }\end{array}$ & $\begin{array}{l}\text { A line treatment where conductors are insulated, and electrical protection is } \\
\text { offered by ACRs (with operational settings adjusted). }\end{array}$ \\
\hline $\begin{array}{l}\text { Insulated OH Insul Eqpt w } \\
\text { ACR }\end{array}$ & $\begin{array}{l}\text { Similar to above, but with an added pole treatment where all pole-mounted } \\
\text { equipment is fully insulated (for example, to prevent animal contact). }\end{array}$ \\
\hline $\begin{array}{l}\text { Insulated OH Bare Eqpt w } \\
\text { ACR \& REFCL }\end{array}$ & $\begin{array}{l}\text { Insulated conductors with bare equipment at poles, ACR (op change) and RE- } \\
\text { FCL protection. }\end{array}$ \\
\hline $\begin{array}{l}\text { Insulated OH Insul Eqpt w } \\
\text { ACR \& REFCL }\end{array}$ & Insulated conductors and equipment, ACR (op change) and REFCL protection. \\
\hline U/G Insul Eqpt w ACR & $\begin{array}{l}\text { Conductors buried underground, and electrical protection is offered by ACRs } \\
\text { (with operational settings adjusted). }\end{array}$ \\
\hline $\begin{array}{l}\text { U/G Insul Eqpt w ACR \& } \\
\text { REFCL }\end{array}$ & $\begin{array}{l}\text { Conductors buried underground, with ACR (op change) and REFCL electrical } \\
\text { protection. }\end{array}$ \\
\hline
\end{tabular}

\subsection{Ignitions}

Calculating the conversion of ignitions to faults is estimated using observed data, experimental data, and expert engineering judgement. Like the fault data, distribution businesses also collect data about known networkcaused ignitions. These data can include information about assets that were involved in the ignition and require repair or replacement, whether the asset ignition converted to a fire in vegetation (a ground fire), and some information about the extent and other consequence of ground fires.

In addition to observational information about ignitions on existing network assets, experimental information has also been commissioned and utilized, particularly in understanding the potential performance of new network technologies. New technology is tested in controlled experimental conditions and the information so obtained then informs the estimation of the proportion of faults that might lead to ignitions. Analysis of observational data in combination with experimental results makes clear that there are several factors influencing the "conversion" of faults to ignitions. One of these factors relates to the total amount and concentration (in time and space) of energy that can potentially be released by the fault. This can be a function of concepts including the "geometry" of the fault (e.g., the relative positions of external elements such as animals or vegetation, and conductors and pole-mounted equipment); the electrical mode of the fault (e.g., phase-to-earth or phase-to-phase flow); and the settings selected for electrical protection technology on the network (e.g., how quickly supply is cut off in the event of a fault detection). The second key component relates to environmental 
factors. On the one hand, this can relate to how much impedence there is to electrical flow along a fault which is related to moisture. These can affect both fault detectability and the amount of energy that is released as heat. On the other hand, this also includes how ignitable materials surrounding electrical assets will be once there has been an energy release.

When considering fault-to-ignition conversion proportions, because ignition data are much more limited than fault data, it is impossible to include all of the situational and condition variables and the cause-and-impact details that are considered in fault rate estimation. Instead, using a combination of observations, experimental results and expert judgement, conversion rates in terms of cause-category is used to inform rates of conversion of faults to ignitions under different environmental conditions.

\subsection{Potential technology combinations}

A number of potential technology combinations that can be applied to substations, sections, and individual lines and poles is considered in the RRM. A listing of base and future asset types is listed and described in Table 1.

\section{RESULTS AND DISCUSSION}

Ignition rate reductions for the technology options listed in Table 1 were calculated based on estimated faults and fault to ignition conversions developed as described in the preceding section. The quoted reductions are averaged over the environmental information (situation, conditions). In Table 2 we report on the case where we calculated the ignition rate reduction based on average annual situation and condition variables. Other cases including assessing ignition risk reduction under the worst fire conditions were also considered but are not reported.

Table 2. Ranges of relative ignition rate reduction for various technology options on average across all levels of meteorological conditions

\begin{tabular}{|c|c|c|c|}
\hline Type & Description of treatment & $\begin{array}{l}\text { Expected } \\
\text { reduction } \\
\text { in ignition } \\
\text { likelihood } \\
(\mathrm{SWER}) \\
\end{array}$ & $\begin{array}{l}\text { Expected re- } \\
\text { duction in ig- } \\
\text { nition likeli- } \\
\text { hood }(22 \mathrm{kV})\end{array}$ \\
\hline Bare-wire & $\begin{array}{l}\text { The base case option is to leave } \\
\text { bare-wire powerlines in place. }\end{array}$ & $0 \%$ & $0 \%$ \\
\hline $\begin{array}{l}\text { ACR operating on bare-wire and in- } \\
\text { stallation of new ACRs, mainly on } \\
\text { SWER lines, that are capable of } \\
\text { remotely have operational settings } \\
\text { changes on bushfire risk days to re- } \\
\text { duce the time taken to clear a fault. }\end{array}$ & $\begin{array}{l}\text { The operational changes are in ac- } \\
\text { cordance with technical recommen- } \\
\text { dations and are one "fast" trip on a } \\
\text { highest fire danger day or two "fast" } \\
\text { trips on other bushfire risk days in } \\
\text { the highest bushfire start risk areas. }\end{array}$ & $-35 \%$ to $-40 \%$ & $-7 \%$ to $-10 \%$ \\
\hline Insulating bare-wire & $\begin{array}{l}\text { Installation with modern HV Aerial } \\
\text { Bundled Conductors (ABC) on the } \\
22 \mathrm{kV} \text { network with insulated equip- } \\
\text { ment connections. }\end{array}$ & $-96 \%$ to $-98 \%$ & $-96 \%$ to $-98 \%$ \\
\hline REFCL & $\begin{array}{l}\text { Bare-wire conductor with new } \\
\text { ACRs at section level and REFCL } \\
\text { protection at feeder level. }\end{array}$ & $0 \%$ & $-48 \%$ to $-60 \%$ \\
\hline Undergrounding bare-wire & $\begin{array}{l}\text { Replacement of bare overhead con- } \\
\text { ductors with underground cable and } \\
\text { insulated equipment connections. }\end{array}$ & $-98 \%$ to $-99 \%$ & $-98 \%$ to $-99 \%$ \\
\hline
\end{tabular}

Being able to calculate electrically caused ignition rates like those in Table 2 is extremely useful. Such calculations provide information that can be used to target particular technology changes (upgrades) to relevant 
network areas (of high risk). The fact that meteorological and situational information can also be modified to reflect changing or future conditions makes this very useful as a predictive tool if combined with urbanisation and/or climate models. In addition to improving network safety, such information could also be used to contribute to broader studies about bushfire natural disasters and how they are changing in Victoria. Similar models could also be developed for other locations. Another key contribution made with the development of this model is in the construction of the databases that it runs off of. Data are not consistent between distribution businesses and other organizations. Also, many variables had to be derived based on text descriptions. In future work, to refine the model, we hope to further improve data both by collecting performance data on newly implemented technologies and cross-referencing ignition data with those collected by emergency service providers.

\section{REFERENCES}

Dowdy, A. and G. Mills (2012a). Atmospheric and fuel moisture characteristics associated with lightning attributed fires. Journal of Applied Meteorology and Climatology 51, 2025-2037.

Dowdy, A. and G. Mills (2012b). Characteristics of lightning attributed wildland fires in south-east australia. International Journal of Wildland Fire 21, 521-524.

Magnussen, S. and S. Taylor (2012). Prediciton of daily lightning and human caused fires in british columbia. International Journal of Wildland Fire 21, 342-356.

Padilla, M. and C. Vega-Garcia (2011). On the comparative importance of fire danger rating indices and their integration with spatial and temporal variables for predicting daily human caused fire occurrences in spain. International Journal of Wildland Fire 20, 46-58.

Penman, T., R. Bradstock, and O. Price (2013). Modelling the determinants of ignition in the sydney basin, australia: implications for future management. International Journal of Wildland Fire 22, 469-478.

Plucinski, M., W. McCaw, J. Gould, and B. Wotton (2013). Predicting the number of daily human caused bushfires to assist suppression planning in south-west western australia. International Journal of Wildland Fire 23, 520-531.

Reineking, B., P. Weibel, M. Condedera, and H. Bugman (2010). Environmental determinants of lightning v. human-induced forest fire iignition differ in a temperate mountain region of switzerland. International Journal of Wildland Fire 19, 541-557.

Wang, Y. and K. Anderson (2010). An evaluation of spatial and temporal patterns of lightning and human caused forest fires in alberta, canada, 1980-2007. International Journal of Wildland Fire 19, 1059-1072. 